\title{
Mujeres Creando: militantes feministas e a arte de habitar o contraditório*
}

\author{
Alessandro José Oliveira**
}

\section{Resumo}

Este trabalho toma o coletivo feminista Mujeres Creando, da Bolívia, e suas atividades criativas de rua para tratar da arte da performance feminista. A partir da problematização da linguagem desenvolvida por algumas teóricas feministas, cunho a noção de "habitar o contraditório" para pensar a presença das mulheres nesta linguagem artística. $\mathrm{O}$ artigo está dividido em três momentos. O primeiro discute a recusa do coletivo Mujeres Creando em definir suas atividades expressivas de rua como arte performática e de sua participação artística em algumas galerias. $\mathrm{O}$ segundo propõe uma reflexão do corpo feminino em ação performática e o dilema que o inscreve simultaneamente no espaço do protesto $e$ do desejo $e$ o terceiro discute as polêmicas em torno da obra "Espaço para Abortar", apresentada pelo coletivo na $31^{\text {a }}$ Bienal de Arte de São Paulo.

Palavras-chave: Arte da Performance, Performance Feminista, Mujeres Creando, Artivismo, Feminismo.

* Recebido em 17 de dezembro de 2019, aceito em 12 de novembro de 2020. ** Pesquisador Colaborador no Departamento de Artes Cênicas, Instituto de Arte, Unicamp, Campinas, SP, Brasil. oliveira.alej@gmail.com / https://orcid.org/0000-0003-3395-8664 
Mujeres Creando: Feminist Activists and The Art Inhabiting The Contradictory

\begin{abstract}
This article discusses the creative street activities of the feminist group Mujeres Creando, from Bolivia, in order to approach the art of feminist performance. With reference to the problematisation of language as developed by various feminist theorists, the article articulates the notion of 'inhabiting the contradictory' to think about the presence of women in this artistic language. The text is divided into three parts. First, it focuses on the refusal of Mujeres Creando to define their expressive street activities as performance art and it questions their artistic participation in some art galleries. Secondly it reflects on the female body in performative action and the dilemma that inscribes it simultaneously in the space of protest and desire. Thirdly, it discusses the controversies surrounding the work "Espaço para Abortar" presented by the group at the 31st Bienal de Arte in São Paulo.
\end{abstract}

Keywords: Performance art, Feminist performance, Mujeres Creando, Artivism, feminism. 


\section{Introdução}

Thomas MacEvilley (2005) observa que a performance está presente entre nós desde os fenômenos ritualísticos delineados na Grécia Antiga. Contudo, o emolduramento que a leva ao status de arte moderna ocorre a partir dos eventos artísticos de 1960, influenciados principalmente pelos movimentos de contracultura feministas, gays e lésbicos norte-americanos. No campo da arte, as performances feministas aparecem como um importante mecanismo político que articula a arte tanto em relação aos movimentos sociais como à subjetividade dos artistas. Essa articulação leva em conta a participação das mulheres no e com o ato criativo, considerando tanto a execução técnica quanto o diálogo com público, também feminino, a qual se direciona a mensagem.

No contexto específico do feminismo norte-americano, Marvin Carlson destaca os trabalhos de Yvone Rainer, Yoko Ono, Meredith Monk. Mas, Sue-Ellen Case, Peggy Phelan e Elin Diamond, que apresentam significativas contribuições para sustentar uma noção de performance artística feminista (Pinho e Oliveira, 2012), dando forma à articulação da arte da performance aos trabalhos teóricos feministas. Jill Dolan (2007) em sua obra Utopia in Performance, por exemplo, analisa diferentes experiências performáticas e artísticas produzidas pelas mulheres entre o período de 1960 a 1970 e aponta a performance como trabalho artístico de futuro promissor da intervenção feminina na cultura.

Partindo dessas considerações observamos algumas performances das feministas anarquistas do grupo Mujeres Creando no cenário cultural da Bolívia e no cenário artístico contemporâneo. A escolha deste grupo se deve a duas características importantes. A primeira é destacar a performance artística de mulheres latinas, ou seja, lançar um olhar para arte produzida em solo americano distante dos epicentros culturais como Nova York ou Boston. Lúcio Agra no seu artigo "Fora do Mapa" aponta as diversas barreiras que impedem um 
mapeamento da performance na América Latina. ${ }^{1}$ Apesar de seus sólidos argumentos, as iniciativas nessa direção implicam numa redução das diversas barreiras e lançar um olhar para performances artivistas feministas acarreta um esforço em contemplar o lugar das mulheres na performance.

Um segundo motivo que alimenta esse investimento parte da perspectiva de pensar as mulheres na performance artística e a performance enquanto linguagem. Butler (2015:58-59) expõe claramente como a questão da linguagem foi acionada com eloquência por diferentes pontos de vistas nas distintas perspectivas teóricas feministas:

Para Wittig, a linguagem é um instrumento ou utensílio que absolutamente não é misógino em suas estruturas, mas somente em suas aplicações. Para Irigaray, a possibilidade de outra linguagem ou economia significante é a única chance de fugir da 'marca' do gênero, que, para o feminino, nada mais é do que a obliteração misógina do sexo feminino. Enquanto Irigaray busca expor a relação ostensivamente "binária" entre os sexos como um ardil masculinista que exclui por completo o feminino, Wittig argumenta que posições como a de Irigaray reconsolidam a lógica binária existente entre o masculino e o feminino, $e$ reatualizam uma ideia mítica do feminino. Inspirando-se claramente na crítica de Beauvoir em $O$ segundo sexo, Wittig afirma que "não há escrita feminina". Wittig acata claramente a ideia de um poder da linguagem de subordinar e excluir as mulheres. Como "materialista", contudo, ela considera a linguagem como uma "outra ordem de materialidade" uma instituição que pode ser radicalmente transformada. A linguagem figuraria entre as práticas $e$ instituições concretas e contingentes mantidas

\footnotetext{
${ }^{1} \mathrm{O}$ autor afirma que o material referente ao tema está disperso e fragmentado, existem dificuldades dos países colonizados se auto afirmarem como produtoras de experimentos próprios ao invés de réplicas da Metrópole, assim como, dificuldades em conceituar América Latina e performance. Ele afirma ainda que não existe material de referência e que encontra enormes dificuldades de financiamento para pesquisas dessa natureza.
} 
pelas escolhas individuais, e consequentemente, enfraquecidas pelas ações coletivas de selecionar indivíduos. A ficção linguística do "sexo", argumenta ela, é uma categoria produzida e disseminada pelo sistema da heterossexualidade compulsória, num esforço para restringir a produção de identidades em conformidade com o eixo do desejo heterossexual (Butler, 2015:58-59).

Assim, o fazer performático das mulheres enquanto linguagem apresenta força suficiente para gerar algumas fricções sobre o lugar simbólico delineado historicamente ou mesmo para criar uma espécie de subcampo que desafia a ordem e define alguns ganhos ou pelo menos instaura um protesto que tende a incidir na exigência da redefinição do jogo. Mas esse ataque ao poder estabelecido pela estrutura machista/misógina/ heteronormativa produz seu reverso, pois os mecanismos que define o masculino como linguagem dominante reinscreve a mulher enquanto o outro do Homem e a performance enquanto linguagem corre riscos de reeditar os elementos que acabam por reinscrever a própria linguagem dominante.

Nesse contexto, embora o corpo feminino na performance apresente valor significativo que determina rupturas com linguagem discursiva do pai, a ordem simbólica dominante tende a recolocar a subordinação. Diante deste sujeito social $e$ historicamente situado, Kristeva (apud Fraser, 1973) vê a possibilidade de práticas sociais romperem parcialmente com as convenções sociais e discursivas reinantes. Um sujeito de práticas potencialmente inovadoras, por assim dizer (Fraser, 2017). Assim, junto às audácias artístico-políticas buscamos acompanhar os percalços decorrentes da inscrição do corpo feminino numa lógica simbólica e/ou numa linguagem dominante que não a comporta totalmente. Nesse sentido, acompanhei alguns atos performativos do coletivo feminista Mujeres Creando, considerando o fazer feminino na arte como um ato subversivo, balizado pelo que nomeei como uma prática de habitar o contraditório. 
Ao ancorar a reflexão na noção de habitar o contraditório buscamos inscrever um elemento retórico capaz de guiar o pensamento. Essa noção é acionada aqui como estratégica para a reflexão. Assim, ao definir a performance do Mujeres Creando como ato que 'habita o contraditório' aponto para o movimento que fricciona e desloca os sentidos, portanto, um gesto capaz de instaurar rupturas no campo político de perspectiva feminista, mas que convive com a subordinação à linguagem dominante.

\section{Entrar pelas brechas}

Marvin Carlson (2004) observa que na década de 1990 o corpo volta a ganhar centralidade, ligando-se a body arte dos anos 1970, cuja temática remetia ao sofrimento e à identidade. É neste contexto que se forma o artivismo do Mujeres Creando. Na década de 1990, a pauta dessas feministas bolivianas girava em torno de uma crítica ao neoliberalismo. Julieta Paredes (2007), ativista do grupo, observa que o Mujeres Creando nasce de três movimentos - Federación Feminina Obrera, Federación Obrera Local e Federación Agrária Boliviana - que, mais tarde, se unificaram em torno do pensamento marxista. Paredes observa que esses movimentos lhes deram clareza a respeito das reivindicações dos trabalhadores da Bolívia e permitiram às mulheres do movimento recuperarem a memória anarquista de suas avós. Neste nascedouro, o Mujeres Creando considerava a base de sua luta o posicionamento contra o Estado neoliberal, contra as ONGs e contra as Igrejas.

Mujeres Creando deixa claro que o discurso neoliberal criava uma armadilha extremamente perigosa, na medida em que cooptava estrategicamente diversas mulheres para dar continuidade ao patriarcado. Assim, o papel que o coletivo se auto atribuía era de problematizar a representatividade das mulheres no governo. Elas afirmavam que as mulheres eram usadas apenas estatisticamente, pois, conforme observam, a representação feminina não pode ser percebida apenas pela presença de mulheres nos cargos públicos, mas pelas condições equânimes no 
poder. Maria Galindo (2013:20), outra representante e fundadora do grupo, reagia contra as mulheres cooptadas pelo governo: "Eles e elas tem o governo, eles e elas tem seus aparatos burocráticos e os contatos para criar campanhas publicitárias, nós temos a rua". Nesse sentido, a rua aparece como lugar privilegiado das atuações do Mujeres Creando e, consequentemente, o lugar de suas performances. Vejamos um exemplo:

Mujeres Creando está instalado em um local estratégico do Centro de La Paz: o Obelisco. Elas estão acompanhadas por um grupo de homens de diferentes tamanhos, idades, etnias e classes sociais. Os homens se despiram $e$ as mulheres começam a pintar seus pênis com pinturas de cores diferentes. Um grupo heterogêneo, mas fundamentalmente popular - a multidão urbana - reúne-se para assistir, como faria para assistir a um ato de rua de artistas de rua ou atores cósmicos. A polícia chega, mas não sabe o que fazer. Será isto um espetáculo artístico, que seria uma forma de discurso permitido ou simplesmente uma violação das leis que proîbem a nudez pública? À margem do público, consultas ansiosas sobre como proceder acontecem. Telefonemas invisíveis. Oficiais de nível cada vez mais alto se envolvem, sem atingir resultados satisfatórios. Fascinação, mas também perplexidade $e$ debate no público. O que está acontecendo aqui? Os repórteres chegam: como vão "representar" esse ato que interrompeu dramaticamente a ordem cotidiana do centro de La Paz? Literalmente é impossível representá-lo como "notícia" - será aludido no noticiário noturno da TV e no dia seguinte nos jornais da cidade (Manifestação Curiosa no Obelisco?), Mas a dificuldade para com o representado não se deve apenas em atenção ao tabu da nudez, mas também porque a relação de poder "normal" entre homens $e$ mulheres foi invertida e transgredida: as mulheres se ajoelham ou se dobram para pintar o pênis dos homens, mas o ato de pintar nega ou carnavaliza sua autoridade, seu status simbólico: o falo. O que fica claro, quando se olha para o vídeo que Mujeres Creando fez deste evento é 
que a performance reside menos no ato de despir os homens de suas roupas e pintar seus pênis que na convulsão produzida pelo público e nas autoridades que os rodeiam e nas ressonâncias que tem mais tarde na cidade $e$ na nação como um todo (Beverley, 2006:12-13).

John Beverley busca alinhar sua narrativa em defesa das convicções do grupo, promovendo um deslocamento do olhar, retirando a carga de importância da performance artística para a performance da recepção. Ele afirma literalmente que o vídeo da referida performance deixa ver uma confusão nos diferentes agentes da plateia que faz do ato subversivo de nudez um ato menor. Sua narrativa acentua a desestabilização do público entendido como mecanismo pelo qual se consolida o ato político.

Ao analisar o Mujeres Creando, Bruna Mendonça (2018:48) observa que este coletivo resiste ao enquadramento artístico. Para essas feministas, o universo artístico é um "lugar, em geral, de cooptação de linguagem, uma vez que trabalha para si mesmo, neutralizando a linguagem autêntica" ${ }^{2}$. Diante disso, a autora observa que o Mujeres Creando prefere considerar o ato performático como parte de um fazer criativo que "excede a arte". Assim, nomear o trabalho como performance artística passa a ser entendido como algo que faz o gesto expressivo refém de um poder externo a ele: a tradição artística.

Esse protesto contra a chancela da instituição artística é significativo para particularizar o feminismo do Mujeres Creando, sobretudo, porque reverbera uma noção mais totalizante a respeito do que o grupo entende como papel das mulheres mediante a tradição artística. Aqui vemos submergir a filiação anarquista do grupo (talvez um compromisso de fidelidade à herança de suas avós anarquistas) delineado pelo desejo profundo de mover as estruturas sociais que reduzem os espaços para uma justa expressão simbólica das mulheres.

\footnotetext{
${ }^{2}$ Para a autora a noção de autenticidade está relacionada a concepção de arte popular onde a espontaneidade de folguedos e demais fazeres populares são recobertos por uma aura de espontaneidade.
} 
A recusa ao enquadramento artístico mais oficial é, portanto, uma maneira dessas mulheres questionarem as instituições artísticas e, consequentemente, a institucionalização da estética produzida pelo seu fazer criativo na rua. Para essas feministas o machismo é uma categoria completamente imbricada com as instituições, inclusive as artísticas, por isso seria impossível defender um lugar para as mulheres dentro do sistema tradicional de arte.

Nesse sentido, a recusa ao enquadramento de expressões contemporâneas de arte é um gesto que busca enfatizar o protesto na rua e, ao mesmo tempo, um jeito de desencorajar qualquer alinhamento de seu fazer criativo com as estruturas machistas, que elas consideram centrais na organização do sistema tradicional de arte. Ainda que a mobilização tenha base estética, o conteúdo informativo dos enunciados tende a dar sustentabilidade e coesão ao projeto de denúncia à opressão contra as mulheres. A única possibilidade que o grupo admite para suas produções estéticas é, portanto, inscrevê-lo enquanto busca contínua de um lugar independente para as mulheres criarem e se expressarem.

É curioso notar que a própria história da performance artística se constitui como uma crítica aos academicismos delineados pelas instituições artísticas e se estabelece enquanto um protesto ao modo mercadológico com que a arte foi, e continua sendo tratada. Segundo Cohen (2002:38), a "live art [por exemplo] é um movimento de ruptura que visa dessacralizar a arte, tirando-a de sua função meramente estética, elitista", ou seja, a performance artística também tem base num protesto às instituições artísticas. Vale lembrar que, ao se ancorar na produção criativa da vida cotidiana de artistas ou não, a arte da performance torna-se um perigo para a própria instituição, pois em última análise ela coloca em xeque a autoridade institucional $e$ a função que lhe assegura determinar quem, como, onde $e$ quando se deve fazer arte. Cohen afirma ainda que: "Ideologicamente, a performance incorpora as ideias da Não-Arte e da chamada Arte de Contestação. As performances do Fluxus reforçam a ideia, proposta por Marcel Duchamp, de que qualquer 
ato é um ato artístico, desde que seja contextualizado como tal" (2002:59).

Uma das consequências deste cenário de ruptura foi delineado pelo esforço por parte das instituições artísticas de cooptação de artistas performáticos para reeditar o poder de sua chancela. O movimento mais contundente das instituições acabou por permitir uma enorme visibilidade às poéticas da rua que passaram a ser acionadas como uma estratégia de manutenção deste lugar de autoridade. No entanto, o resultado deste esforço gerou um estado de desconfiança que delineou a recusa de diversos artistas aos espaços tradicionais de arte.

Embora apresentadas como meios de intervenção na rua, as formas estéticas produzidas pelo Mujeres Creando alcançam validade artística de obras que não ficam circunscritas ao campo das instituições. Ou seja, por mais que sejam pensadas enquanto meio para se atingir o efeito de um ato político, as ações performáticas deste coletivo de mulheres acabaram sendo legitimadas como algo de valor pelo universo artístico sensível a arte da rua.

Os elementos estéticos que dão plasticidade aos atos políticos são integrantes, indissociáveis e ultrapassam o esforço que busca negá-los enquanto status artístico. Se olharmos mais uma vez para a descrição de John Beverley (2006) vemos que mesmo ao enfatizar o ato político e sua narrativa não rebaixa o gesto artístico, ele descreve que o público da performance do Mujeres Creando se sente atraído "como faria para assistir a um ato de rua de artistas de rua ou atores cósmicos" (2006:12). Assim, os elementos poéticos inerentes ao ato performativo são pensados como atributos que dão ao gesto militante uma capacidade de ritmos e harmonias capazes de ultrapassar as manifestações políticas tradicionais, isto é, o ato criativo formata o ato político.

Rui Mourão (2015) afirma que a tradição artística ao acentuar a "arte pela arte" permitiu um invólucro conceitual para a Arte que busca controlar as formas experimentais por critérios estabelecidos pela elite. Contudo, a pequena abertura para o 
experimento permitiu o crescimento de práticas fora do enquadramento. A história da arte da performance apresenta diversos mártires. De Marina Abramovic, que em 1969 teve sua obra Come wash with me recusada, a António Manuel, que em 1970 apresenta-se nu no $19^{\circ}$ Salão Nacional de Arte Moderna do Rio de Janeiro, depois de ter seu trabalho "O corpo é a Obra" rejeitado pelo júri do evento (Santos, 2008). De igual modo, alguns performers estabelecem uma recusa mais radical em coabitar com as instituições e recusam a chancela de seus membros. Mourão destaca a polêmica em torno do trabalho levado adiante pelo coletivo Liberate Tate, em Londres, que nasce de um workshop promovido pela Tate Modern em 2016, recusa o cerceamento da galeria sobre suas ações artísticas contra petrolíferas como a British Petroleum, mecenas da própria Tate Modern. As convicções ecológicas dos participantes da Liberate Tate geraram conflitos e protestos em formas de performance contra a captura da arte/museus pela lógica capitalista.

Essas práticas fora do enquadramento subverteram a autoridade dos considerados entendidos da arte e expandiram a concepção de arte de modo a contemplar a "dimensão simbólica interventiva no real" (Mourão, 2015:63). Assim, o cenário artístico enquanto espaço de disputa permanente abriu brechas capazes de acolher e incorporar o fazer artístico de diferentes grupos artivistas denominadas por Mourão como "arte atuante". Ainda segundo Mourão (2015:63), "esse tipo de arte questionadora do status quo e procura estar não só ao serviço dos interesses de alguns, de uma subcultura, mas ao serviço da sociedade como um todo".

Apesar do controle do sistema de arte ser praticamente dominado por uma aura elitista, o fazer criativo do Mujeres Creando também encontrou aliados interessados em reorganizar os espaços artísticos. Ao forjar a presença de determinados fazeres artísticos no campo das representações oficiais, esses aliados também revelam o cenário das disputas simbólicas. Isso nos leva a pensar que existem curadores dispostos a propagar noções mais amplas de arte que, inclusive, abarcam expressões ausentes das galerias. Mesmo com a recusa e a crítica ao sistema de arte, o 
Mujeres Creando foi incorporado como representativo no cenário da arte contemporânea.

Mourão observa ainda "que na realidade os campos da 'arte pela arte' e de uma 'arte atuante' raramente são mutuamente exclusivos e estanques, no entanto, o artivismo tem-se vindo a afirmar como a vanguarda mais radical, interdisciplinar e arriscada da ação artística no real" (2015:63). Assim, apesar do trabalho artístico depender de uma série de agentes envolvidos no campo da produção simbólica destinados a estabelecerem os critérios de validação de suas obras $e$, apesar destes agentes serem responsáveis diretos por ligar a obra à tradição artística (supostamente em diálogo com o nosso tempo), o cenário de dissensão tem permitido construir uma abertura significativa nos espaços oficiais e lançar um olhar igualmente significativo para as artes da rua e a performance atuante.

Se os espaços mais conservadores recusam a convergência entre a criação artística $e$ a ação política, acusando essa junção como uma atitude panfletária onde se almeja instrumentalizar a arte, o argumento dos "dissidentes" consiste em acusar a arte apresentada como neutra tão comprometida quanto a arte engajada. ${ }^{3}$ Para os defensores da arte atuante, as manifestações ditas neutras são os exemplos mais contundentes de instrumentalização da arte, na medida que se apresentam em função dos interesses dos agentes sociais dominantes. Assim, a chamada arte pela arte se inscreve em uma dinâmica panfletária de enaltecimento dos valores burgueses, de modo que os artistas dependam de contatos profissionais, lobby comercial de galerias e diversos elementos que ultrapassam a intrínseca qualidade da obra.

\footnotetext{
${ }^{3}$ A suposta neutralidade reivindicada pelos experts é entendida aqui como um comprometimento político com a produção estética da elite. Neste sentido, a arte dita neutra é uma arte engajada tal como a arte produzida pelas feministas, movimento gay, movimento negro, etc.
} 


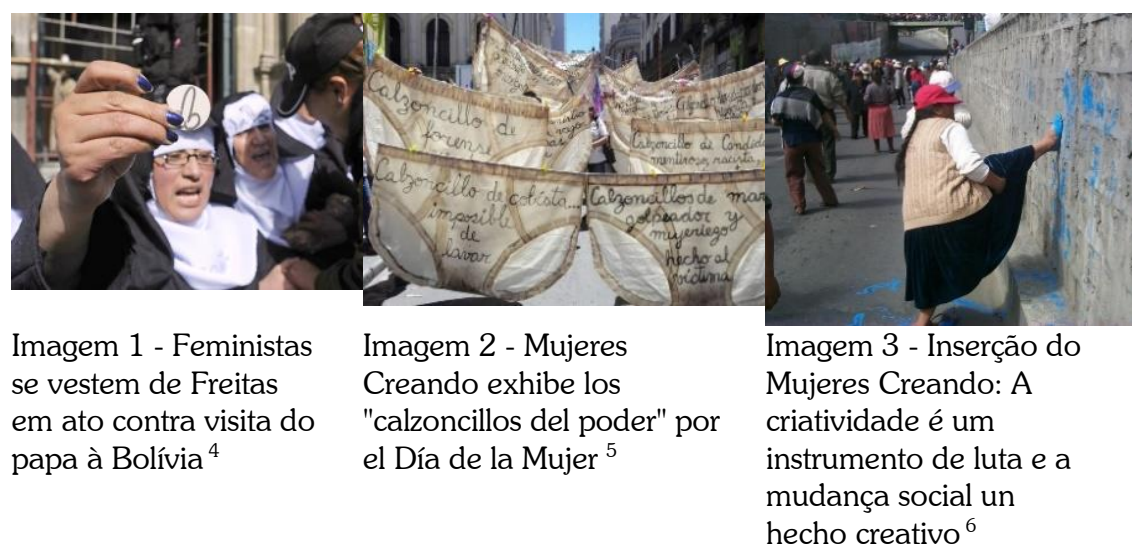

Nesse contexto de disputa, a arte da rua torna-se objeto de interesse tão legítimo quanto qualquer outro e passa a ser defendida tanto como bandeira da liberdade de expressão como pela recusa da noção de pureza (de uma arte pela arte) que lhe cobre de certa aura sagrada, conduzindo-a a altares museológicos $e$ ao status de objetos intocáveis. Junto com isso, a aceitação de uma postura que privilegia o fazer individualista (a assinatura do autor) tem em contrapartida os protestos que levaram a valorização da obra coletiva e sua dimensão interventiva. Dessa maneira, o ato criativo imbuído pelo ato político (e vice versa) das feministas do Mujeres Creando são inscritos no campo da arte contemporânea.

Em 2014, o coletivo foi convidado para a $31^{a}$ Bienal de Arte de São Paulo na qual produziu a obra "Espaço para abortar". Em

\footnotetext{
${ }^{4}$ Imagem 1, Fonte: https:/www.icatolica.com/2015/07/feministas-se-vestem-defreiras-em-ato.html

5 Imagem 2, Fonte: https:/www.paginasiete.bo/sociedad/2019/3/8/mujerescreando-exhibe-los-calzoncillos-del-poder-por-el-dia-de-la-mujer-211366.html

6 Imagem 3, Fonte:https:/www.afterall.org/journal/issue.46/mujeres-creandoinsert
} 
2017, a convite de Paul Preciado 7 , o grupo esteve no Documenta 14, em Atenas, com "Sedícion Feminista" e, neste mesmo ano, essas mulheres apresentaram "El Milagroso Altar Blasfemo" na Bienal Internacional de Arte SIART, na Bolívia. Ainda em 2017, elas apresentam "La intimidad es política", no MET, em Quito e a obra "Enclaustrados en sus patrioterismos", no Museu Salvador Allende, Chile. Esta obra em particular trouxe à tona uma reflexão crítica a respeito da substituição simbólica da figura dos indígenas por animais em diversos ícones do processo colonizador da cultura chilena e a uma série de questões que revelaram certos imbricamentos entre a produção artística do Chile e da Bolívia, pois ao refletir sobre o escudo chileno o grupo se deu conta das semelhanças entre ele e o escudo boliviano (Flores, 2017). A partir disso, passaram a questionar com mais veemência a produção artística de seu próprio país.

Notadamente, a atuação política do Mujeres Creando deu forma a projetos artísticos expostos em diferentes galerias. O que promove o alinhamento de ações entre as galerias de arte, inicialmente resistentes à arte da rua $e$ aos atos políticos/artísticos de uma militância que recusa a ser arte, pode ser mais inteligível ao analisamos suas primeiras participações artísticas em espaços consagrado da arte: convidadas pelo Museu Nacional Reina Sofia, Madri, o grupo apresentou a obra "Ten cuidado con el presente que construyes, debe parecerse al futuro que sueñas" (2000/2001) $e$, nessa ocasião, Galindo observa a necessidade de usar o sistema contra ele, entrando pelas suas brechas. ${ }^{8}$

${ }^{7}$ Paul B. Preciado, filósofo transgênero, contribuiu para o desenvolvimento da teoria Queer e a revisão de conceitos ocidentais ligados a identidade, gênero, sexualidade e feminismo.

8 "En ese momento nosotras necesitábamos dinero, así de claro, pero también éramos muy conscientes del valor que tenía el lenguaje que nosotras estábamos lanzando y éramos muy conscientes también de que estábamos en Bolivia, en un escenario de una desvalorización de nuestro trabajo; éramos, y seguimos siendo, las locas oficiales. Seguimos sufriendo mucho machismo, mucha misoginia $e$ inclusive violencia directa contra nosotras y el mundo del arte en Bolivia... bueno, no solamente en Bolivia... es un mundo controlado por una oligarquía blanca de clase media alta, racista, clasista y homofóbica que desprecia 
De acordo com a publicação do Museu (Museo Nacional Centro de Arte Reina Sofía, Colectivo Mujeres Creando, 12 dez/2000 - 14 jan/2001), o trabalho prescinde de qualquer conceito de uma obra que possa ser colocada, exibida ou mostrada em qualquer coleção. $\mathrm{O}$ projeto apresentado pelo Mujeres Creando consistia apenas em alguns vídeos de suas ações, nascidos da relação entre o grupo e um programa de TV denominado "Criando Mulheres", exibido entre maio e agosto de 2000 na rede de televisão $\mathrm{PAT}^{9}$, em La Paz.

Ainda de acordo com o Museu, nos vinte primeiros dias da exposição os visitantes contavam com a presença de Maria Galindo, Julieta Paredes y Florentina Alegre para conversar no salão da galeria. O espaço Uno apresentou ainda algumas pichações, como "Jamás corazón de piedra" ou "Así como tú me quieres, yo no quiero ser de ti", recorrendo às pichações do coletivo nas ruas de La Paz.

profundamente nuestro trabajo y entonces era muy interesante cuestionar ese control del mundo del arte por parte de la oligarquía, a través de participaciones dentro de las instituciones que esa propia clase social desea y ansía, puesto que son sus referentes y modelo a seguir. Con esa invitación puntual nació la relación de Mujeres Creando con el arte, pero nunca dejamos de ser críticas del mismo. Nosotras tenemos una postura muy crítica, pero también tenemos una relación que es utilitaria con los espacios oficiales del mundo del arte. También tenemos una postura política, es decir, por el carácter colonizado de los espacios culturales bolivianos, Mujeres Creando entra en la discusión central de la política boliviana desde España y no desde las calles bolivianas. Entonces, es bien peculiar lo que sucede, pero nosotras estamos muy convencidas de que la legitimidad de Mujeres Creando no se la da el MNCARS o la Documenta o cualquier otro museo: Mujeres Creando es un referente de rebeldía y de lucha ineludible en Bolivia". In:https://artishockrevista.com/2017/09/28/mujeres-creando-entrevista/

${ }^{9}$ Este projeto abordou temas como ditadura, justiça, racismo, trabalho, ajuda financeira às ONGs, construção da imagem das mulheres, diferença sexual $e$ utopia. 


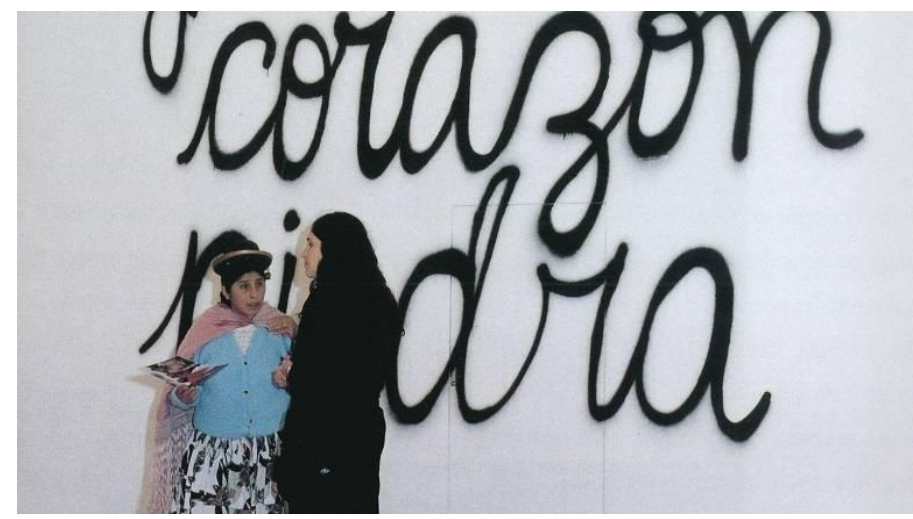

Imagem 4 - Vista de sala de la exposición. Mujeres Creando. Ten cuidado con el presente que construyes, debe parecerse al futuro que sueñas ${ }^{10}$

Mesmo com seu posicionamento crítico acerca do enquadramento artístico de suas atividades ou sua resistência a esse enquadramento artístico, acusando o tradicional sistema de arte de agente de manutenção do machismo estrutural, o projeto de exposição em galeria é bem sucedido, pois ele se alinha à intenção dos curadores em trazer o mundo externo do protesto de mulheres contra a opressão masculina para o mundo interno da galeria e ao desejo de militar dentro das galerias por parte do Mujeres Creando.

Ao acompanhar essa trajetória artística feminista, podemos observar que os trabalhos apresentados dentro do Museu Reina Sofia não facilitam o evento artístico, sobretudo, ao utilizar telas de tv com objetivo de reproduzir suas performances e recuperar suas pichações de rua. Assim, esta arte feminista nos ensina a habitar o contraditório, pois mesmo com as restrições aos enquadramentos institucionais, o grupo não se nega em participar dos espaços

10 Imagem 4, fonte: https://www.museoreinasofia.es/exposiciones/mujerescreando-ten-cuidado-presente-que-construyes-debe-parecerse-al-futuro-quesuenas 
oficiais de exposições de arte. Mesmo com a justa problematização e crítica ao sistema de arte formal, não houve uma recusa radical aos convites de participar em diversas galerias. E é importante sinalizar ainda que esse convite a habitar o contraditório conferiu vantagens significativas, sobretudo, ao propor desafios importantes aos projetos apresentados à curadoria e a expansão de suas reivindicações e produções simbólicas. Cabe-nos indagar: este projeto inscreve um fazer artístico especificamente feminista? Seria esse gesto uma forma de habitar uma linguagem com uma não linguagem?

Se não existem respostas certeiras para essas indagações, os trabalhos do Mujeres Creando instauram uma sensibilidade que passa pela sua "dor", pela alteridade e pelo protesto, reverberando em um espaço institucional que responde criticamente ao elitismo da arte e expande o campo da estética formal para a arte atuante. Uma arte que estabelece como princípio norteador a tomada das ferramentas da cultura como ato político para empregá-las em outra direção. Mujeres Creando imprime um jeito de habitar o contraditório como estratégia de guerrilha anarco-feminista e instaura a ausência da materialidade da obra e o lugar de fala de mulheres que esperam seu público no salão da galeria (lugar político militante). $\mathrm{O}$ vazio de sua ausência na linguagem é explorado, mesmo que inconscientemente como presença.

A conjuntura que envolve tanto o Mujeres Creando quanto a preocupação pela emergência de uma arte dissidente delineada pelo Museu Reina Sofia instaura as condições necessárias que levam este coletivo de mulheres a habitar o contraditório. Como apontaremos esta condição de habitar o contraditório pode ser encontrado em diferentes momentos do fazer artístico do Mujeres Creando.

A noção de habitar o contraditório aqui sustentada funciona como um guia para refletir sobre o fazer deste grupo feminista que não se esgota na relação entre o fazer da rua e os ditames da arte oficial. Ao aplicar essa noção às ações performativas e militantes do grupo e ao lançarmos um olhar mais acentuado para o corpo 
feminino em atuação performativa nos deparamos com um cenário sui generis que trouxe à tona uma possibilidade de leitura sobre o fazer artístico deste grupo.

\section{Eterno retorno}

Nada é tão desafiador do que o corpo que se expõe $e$ convoca, mas o corpo das mulheres em particular, ao habitar a linguagem dominante, enquanto outro do Outro, fica circunscrito à lógica da subordinação. Por isso, a exibição do corpo feminino, que a princípio coloca as mulheres como dona de seus discursos $e$ numa perspectiva de empoderamento, acaba inevitavelmente gerando sua subordinação. Henri-Pierre Jeudy, ao analisar a performance de Elisabete Mileu (2002:116), nos dá um significativo exemplo:

...em uma bienal de Paris [Mileu] colou na parede duas baguetes de pão, mantendo-as com adesivo vermelho, depois, toda nua, o corpo coberto por um pigmento prateado, ela brincou com esse símbolo realista, lambendo$\mathrm{o}$, mordendo-o, acariciando-o, colocando-se diante dele como se fosse ser violada. No fim, ela coloca fogo nas baguetes usando bombas que produzem fumaça, $e$ o sexo masculino começa a queimar, depois a se consumir, para não deixar senão o traço negro de sua presença. Elisabete Mileu, tendo concluído seu ritual, sai da sala rastejando por entre o público e desaba no pátio em meio aos arbustos.

O sociólogo observa que a performance de Mileu, ao supor denunciar o machismo social, acaba por exaltar o falo. Mesmo quando a artista coloca fogo na baguete - momento em que a artista introduz uma intenção de paródia ao evento -, a proposta de liberdade absoluta das mulheres gera uma atitude sacrifical.

Segundo a descrição de John Beverley sobre a performance do Mujeres Creando: 
Elas estão acompanhadas por um grupo de homens de diferentes tamanhos, idades, etnias e classes sociais. Os homens se despiram $e$ as mulheres começam a pintar seus pênis com pinturas de cores diferentes..." Um pouco mais adiante Beverley descreve que "as mulheres se ajoelham ou se dobram para pintar o pênis dos homens, mas o ato de pintar nega ou carnavaliza sua autoridade, seu status simbólico: o falo... (Beverley, 2006:12-13).

A narrativa de Beverley enaltece o evento e a ação das mulheres que promove confusão geral. Um ato político e artístico que também ganha forma de uma pedagogia popular. Em uma analogia à análise de Jeudy, a respeito da performance de Mileu, é possível considerar que, ao ajoelharem-se diante do pênis, as mulheres do coletivo boliviano poderiam estar reinstaurando a mensagem opressora que desejam criticar. Esse ato valida a proposição de habitar o contraditório que guia nossa reflexão.

É preciso acentuar que nas ações performáticas o acionamento do corpo é um elemento de afetação e, por isso, constitui um dos elementos recorrentes no mundo das artes performáticas. No ato performático o corpo é, e sendo, instaurase. Enquanto uma extravagância no espaço público, o trabalho delineado pelo corpo em performance artística marca presença como elemento estético que gera incômodo.

No entanto, ao acionar o corpo feminino (inscrito pela e na linguagem dominante), as mulheres acabam por experienciar diversos dilemas, um deles é que o corpo das mulheres aciona esse habitar o contraditório. ${ }^{11} \mathrm{De}$ linguagem de protesto ele passa a funcionar como elemento que alimenta o desejo masculino. Devido a isso, Sue-Ellen Case (1988, p.120) nomeia as

${ }^{11}$ Em um encontro sobre o "Corpo Político" em um atelier na cidade de Campinas, uma artista confessou que depois de uma experiência ruim passou a usar barro no corpo nu como medida de proteção, o barro foi o meio que ela encontrou para se desvencilhar dos olhares obscenos dos homens que seguiam ao seu lado numa marcha performativa. Seu corpo seminu em protesto não resultou em uma mensagem desafiadora, ao contrário, instaurava constrangimentos e a expôs a uma condição vexatória. 
performances feministas como um ato que transforma as mulheres em cortesãs culturais, pois, segundo ela, as mulheres não têm os mecanismos culturais que permitem constituírem-se como donas de sua arte.

Vemos aqui que a condição do corpo feminino em espaço performático instaura a fissura e abarca aprisionamentos. Nesse sentido, o corpo feminino no contexto do anarquismo proposto pelas ações praticadas pelo Mujeres Creando apresenta-se como ruptura para o controle do Estado, mas reverte na subordinação a tirania delineada pelo desejo masculino. ${ }^{12}$ Mesmo quando posto conscientemente à serviço de um ato político, o corpo denuncia a insatisfação e cria um novo lugar, uma alternativa, uma obliteração às convenções sociais e discursivas reinantes (Kristeva, 1973), mas inevitavelmente também se apresenta como uma operação cultural e política que reedita, a contragosto, o efeito da linguagem significativamente opressivo para as mulheres, pois, o corpo é sempre percebido na perspectiva hegemônica. Spivak (2010:66-67) recorda que "no contexto da produção colonial, o sujeito subalterno não tem história e não pode falar, o sujeito subalterno feminino está ainda mais profundamente na obscuridade". Áran (2009:659) observa que Lacan traz o falo para o centro da formulação da sexuação, fazendo-o reinar como significante do desejo. Esse constructo estabelece as mulheres como ausência (como "não-toda") e, ao conceber o feminino pelo modelo da dominação masculina Lacan, estabelece que "a mulher não existe" (Áran, 2009:659). Ao analisar a produção fotográfica de artistas da Argentina, David Foster (2007) acentua que qualquer indivíduo construído como o Outro de uma ancoragem masculina fica subordinado a esse olhar, mas é sobretudo o corpo da mulher que está submetido a esta amarração. Assim, a possibilidade do corpo feminino subverter os papéis socialmente

\footnotetext{
12 Conforme observa Carlson (1997:38): “A arte visual e as artes do espetáculo tradicionais estão baseadas num sistema patriarcal que assume o Homem como espetador e a Mulher como o objeto de contemplação desejosa do Homem.
} 
desenhados para o gênero e mesmo o próprio gênero segue como um desafio a ser enfrentado pelo campo da artes.

Elin Diamond (1997) sugere que a performance artística feminina deve fazer uso da ironia, que ela denomina de mimicry, como mecanismo capaz de subverter o efeito da linguagem sem se submeter ao ato sacrifical; Luce Irigaray (1985) propõe que as mulheres devem jogar com a mimese, como algo que permita converter uma forma de subordinação numa afirmação $e$, assim, começar a frustrar essa subordinação. (apud Pinho \& Oliveira, 2012:67).

Pinho e Oliveira (2012:70) observam que a revisão crítica das performances feministas tem apontado que uma das alternativas tem sido explorar a biografia pessoal e direcionar a atuação ao público especificamente feminino. Nesse contexto, consideramos a performance "Aceito", trabalho solo da boliviana Wara Urquiola apresentado no evento Latitudes (2018), em Santa Cruz, Bolívia, bastante significativa. Nesse trabalho, a artista se apresenta vestida de noiva e interage com as mulheres do público, solicitando abraços. Depois, ela senta para moer e comer chilli, provocando reações corporais como choro e fluidos nasais. Essa situação desencadeia uma série de reações no público que colabora com a artista oferecendo água, um elemento de conforto. $\mathrm{O}$ vestido de noiva traz à tona uma imagem potente a respeito da condição das mulheres em relação ao matrimônio. A performance trabalha com a expectativa das mulheres, e do lugar do feminino, na conjuntura do casamento e tensiona o sentido que almeja alternar entre libertação do domínio do pai e a subordinação ao domínio do marido, um trabalho que conversa com a subjetividade feminina, apontando os atravessamentos que as identificam.

A busca de uma proposta desestabilizadora tem permanecido no horizonte das performances feministas e a auto referência delineada pela autobiografia esbaram numa armadilha. $\mathrm{O}$ fortalecimento do individualismo contra as ações coletivas $e$ ativistas fornece fundamento substancial para a agenda política conservadora que tem se espalhado por diversos países. Embora 
criticado por diversas vertentes políticas, o acionamento do experimentalismo pessoal atende mais fortemente às políticas neoliberais de direita que o desejo emancipatório dos artistas. Por isso, a busca por processos delineadores de alternativas implica necessariamente numa revisão crítica, apoiado em diversas reflexões teóricas que insistam em seus projetos de resistência.

\section{A potência em risco}

Ainda na perspectiva de pensar o corpo feminino em performance é mister considerar o trabalho do Mujeres Creando sobre a pauta do aborto ${ }^{13}$. Em 2014, a 31 ${ }^{a}$ Bienal de Arte de São Paulo $^{14}$ oferece ao público o trabalho "Espaço para Abortar" produzido pelo coletivo, convidando as militantes bolivianas María Galindo, Esther Argollo e María Idoja para inaugurar a exposição. Nesta ocasião, as feministas do Mujeres Creando ligaram-se a um conjunto de mulheres brasileiras também militantes e marcharam pelo parque Ibirapuera em protesto contra a penalização da mulher que aborta.

${ }^{13}$ O tema do aborto retorna ao escopo da militância do Mujeres Creando em 2017, quando Maria Galindo se apresenta numa Conferência no México discorrendo sobre a necessidade de dar voz as mulheres: "no caso do aborto, não se trata de dar voz aos senadores e aos médicos ou mesmo conhecer determinadas cifras, mas sim escutar a mulher que abortou". Apesar da centralidade do depoimento das mulheres que abortam, escapa à militante uma leitura crítica a respeito do efeito da exposição das mulheres que abortam e, consequentemente, a possibilidade de sua re-vitimização. Conferência sobre o filme 13 Horas de Rebelion realizada no Instituto de Investigaciones Sociales UNAM - México. https://www.youtube.com/watch?v=ekIOn2UZ9TI

${ }^{14} \mathrm{Na} 31^{a}$ Bienal de Arte de São Paulo, o grupo assina um documento contra o financiamento de Israel à Bienal e revela sua relação com a instituição, reforçando a necessidade de explorar as próprias contradições dos espaços institucionais. [https://www.mujerescreando.org/pag/activiades/2014/1409bienalSaoPaulo/prensa/141016xereca.html. Acesso em: 13/01/2018] 


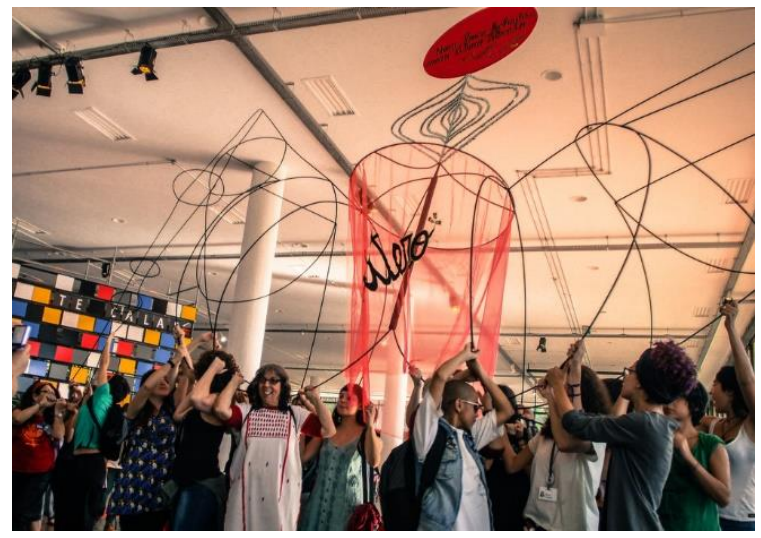

Imagem 5 - Espaço para Abortar ${ }^{15}$

Durante a performance, a caminhada era interrompida para ouvir relatos sobre aborto, mostrando como as mulheres permanecem donas de si e decidem sobre seus corpos à revelia do poder oficial e das diversas tentativas de controle do Estado. $\mathrm{Na}$ ocasião, o grupo carregava uma escultura metálica que representava as pernas abertas de uma mulher e expunha um útero envolto de tecido vermelho transparente. Acima da estrutura havia uma vagina espelhada e uma placa: "Nem boca fechada e nem útero aberto".

O evento foi envolto de controvérsias, segundo Bruna Mendonça (2018:86):

Durante as falas, um homem, cuja filha abortou, quis falar e não lhe foi permitido. Ele ficou nervoso e insistiu, mas mesmo assim não houve concessão das autoras e do público que se envolveu na discussão, já que se configurava em um espaço para os sujeitos diretos do aborto. Isso gerou um incômodo, que podemos pensar no sentido de que os espaços já são majoritariamente masculinos e ainda assim quando se cria um espaço em que as mulheres são protagonistas há uma dificuldade em conceder a fala a elas.

${ }^{15}$ Fonte: http://spressosp.com.br/2014/09/09/espaco-para-abortar/ 
A voz silenciada de diversas mulheres aparece aqui como fundamental, mas também se evidencia a dificuldade em estabelecer um deslocamento entre a violência de gênero $e$ a biologia dos corpos. O controvertido mecanismo de retorno à perspectiva essencialista de gênero reinstaura a perspectiva daquilo que se julga combater.

Ainda que equivocado, o ato em si instiga a algumas indagações: seria a participação dos homens um obstáculo ao protagonismo das mulheres? O equívoco desse participante estaria na sua tentativa de participação ou em tentar falar por uma mulher, ainda que seja sua filha? Em que perspectiva sua voz retira o protagonismo das mulheres em marcha?

Obviamente, não temos respostas para essas questões, contudo, a marcha do Ibirapuera revela o quanto estamos presos à ficção de gênero e como a linguagem dominante reinstaura uma biopolítica difícil de combater: o dispositivo cultural da ilusão da determinação biológica dos corpos. Entender que as mulheres não precisam do apoio (nem da autorização) dos homens para agir (para falar) não implica em recusar a participação dos homens na luta feminista. Dar concessão à voz masculina não implica necessariamente reduzir a potência feminina, a não ser que acreditássemos que todos os homens estão completamente envoltos em posições machistas e heterossexistas... Fica a pergunta: podemos ou não reconhecer que nem todos os homens concordam com a manutenção dos lugares socialmente moldados para as mulheres? Se a respostas for sim, então o episódio em si revela certa dificuldade em suspender a intransponibilidade das estruturas sociais que se almeja e desvela que apesar da luta a estrutura continua operando.

Depois da Marcha, na área de exposição da Bienal, o local destinado ao "Espaço para Abortar" se configurou com um conjunto de cones transparentes denominados "úteros", no qual se podia ouvir os relatos de aborto colhidos durante a Marcha, gerando outras controvérsias. A comissão educativa da Bienal apresentou uma restrição do acesso à obra, interpretada pelo Mujeres Creando (e outros grupos de mulheres associados a elas) 
como censura, já que as feministas defendiam tratar-se de um trabalho voltado para jovens e crianças. Por outro lado, a organização da Bienal afirmou que a prática consistiu apenas em seguir as diretrizes legais de indicação de público definida pelas leis brasileiras, que restringia o acesso aos menores de 14 anos para obras com aquelas características.

Contudo, um fato importante ligado ao "Espaço para Abortar" precisa ser evocado. Segundo a socióloga Milena Costa de Souza (2017:07):

no dia da caminhada o conservador Instituto Plinio Corrêa de Oliveira (IPCO) foi até o evento para fiscalizar a procissão e filmar o acontecimento. Dois homens registraram o percurso e utilizaram as imagens para produzir um vídeo publicado no youtube no qual afirmavam que o Mujeres Creando é contra Deus e possui um discurso radical de apologia ao crime. Em 4 de outubro de 2014 o IPCO realizou um ato público de reparação pelas blasfêmias e sacrilégios da $31^{\text {a }}$ Bienal. Segundo eles: "A $31^{\text {a }}$ Bienal de artes" de São Paulo está promovendo um conjunto escandaloso de blasfêmias e sacrilégios contra Nosso Senhor Jesus Cristo e a Santíssima Virgem (IPCO, 2014).

Não sabemos a força desse grupo para sustentar uma hipótese que implique numa influência significativa na decisão da restrição de acesso à obra "Espaço para Abortar", mas é perceptível que com o tema "Como falar de coisas que não existem" esta Bienal em particular possibilitou a exibição de diversos trabalhos polêmicos que poderiam receber marcas restritivas. Assim, o protesto do Mujeres Creando aparece como uma possibilidade de permuta simbólica, de modo que a acentuação da rivalidade é também uma tática de criação de obstáculo ao discurso hegemônico. Se o lugar do privilégio masculino combate tal ousadia, o lugar do feminino gera solidariedade e questionamentos aos acordos tácitos delineados pelo machismo e pela misoginia estrutural. 
Nessa guerra dos sexos, a ousadia deste coletivo feminista põe em discussão a suposta naturalidade da assimetria dada pela posição que cada gênero ocupa e permite pensar sobre o ato dos agentes no espaço socialmente organizado, abrindo a possibilidade para redefinir o caminho, ou ao menos insinuar, outros jogos possíveis, e fortalecendo o grupo e a potencialidade de aflorar propostas multidimensionais. A ousadia é, portanto, reveladora dos poderes atualmente conformados com uma denúncia ao poder hegemônico e uma demonstração dos poderes que estão sendo erigidos.

Mas é preciso acentuar que, ao menos no caso do "Espaço para Abortar", a forma conturbada de habitar o contraditório expõe uma solidariedade formada por um tecido de afeto entre as mulheres, que acaba por gerar demandas que ganham formas de ações coletivas favoráveis ao fortalecimento da condição feminina enquanto uma espécie de inversão a dominação masculina, ou seja, uma dominação feminina. O protesto inscreve "um lugar de fala" que joga com dor e prestígio, sofrimento e fama. Apesar do risco, essas condições também geram novas formas de se perceber $e$ de ser percebido, de reconhecer e ser reconhecido. Assim, a busca pela legitimidade da luta feminina operacionaliza o desconforto (uma constante na vida das mulheres) que passa a ser acionado para angariar alguns ganhos. Pinho \& Oliveira (2012:71) apontam que muitas performances artísticas feministas aparecem como um "meio de politizar e demonstrar a raiva e a frustração sentidas por muitas feministas" 16 e que a oscilação entre raiva e dor tem delineado diversas práticas feministas.

Em La Paz ou em São Paulo a dimensão da resistência, sobretudo, o efeito moral e a dimensão de ampliação dos modos de lidar com o corpo feminino se conjugam na conformação de um lugar eticamente necessário, comprometido com a quebra de diversos paradigmas e com a criação de outras narrativas. Esses

\footnotetext{
16 Os autores apontam o trabalho de Sara Ahmed (2004) como uma referência importante para pensar a raiva como elemento motivador do ativismo feminista e queer.
} 
caminhos permitem desnudar os impasses entre os gêneros $e$ desobstruir o obscurantismo dos setores mais conservadores filiados ao poder, tanto na instância política como nos espaços da arte.

Em busca de inscrever seu corpo sobre outra perspectiva, artistas de lá e de cá procuram romper com a abjeção, uma proposta politicamente difícil uma vez que se inscreve na margem do pensamento. Vale reforçar que é por meio dele que se busca desafiar a centralidade masculina: as mulheres enquanto ontologia periférica empurram a fórcipes a masculinidade tóxica para um lugar de incômodo no qual foram alocadas, buscando romper com o que historicamente lhes foram atribuídos $e$, apesar das poucas garantias, luta-se para que esse processo não tenha volta.

\section{Referências bibliográficas}

AGRA, Lucio. Fora do Mapa, o Mapa - performance na América Latina em dez anotações. ARS, São Paulo, 2016, v.14, n.27, 2016, pp.135148 [https://doi.org/10.11606/issn.2178-0447.ars.2016.117627_acesso 10 out, 2020].

AHMED, Sara. The cultural politics of emotion. New York, Rutledge, 2004.

ARÁN, Márcia. A psicanálise e o dispositivo diferença sexual. Revista Estudos Feministas, v.17, n.3, Florianópolis, set/dez 2009 [scielo.br/pdf/ref/v17n3/v17n3a02.pdf - acesso em 10 out 2020]

BEVERLEY, John. Prefácio. In: MONASTERIOS, Elisabeth. (org.) No Pudieron com nosotras. El desafío del feminismo autónomo de Mujeres Creando. La Paz Bolívia \& University Pittsburgh, Plural Editora, 2006.

CARLSON, Marvin. Performance: A critical introduction. New York, Routledge, 2013.

CARLSON, Marvin. Performance. Belo Horizonte, Ed. UFMG, 2009.

CARLSON, Marvin. Performance: A critical introduction. New York, Routledge, 1996.

CASE, Sue-Ellen. Feminism and theatre, New York, Methuen, 1988. 
COHEN, Renato. Performance como linguagem, Ed. Perspectiva, 2002.

DIAMOND, Elin. Unmaking mimesis. London, Routledge, 1997.

DOLAN, Jill. Feminist Performance and Utopia: A Manifesto. In: CASE, Elaine Astor e Sue- Ellen (org.). Staging international feminisms. New York, Palgrave Macmillan, 2007, pp.212-221.

FLORES, Mariairis. Mujeres Creando: El Neoliberalismo há tomada la Cuote de las Mujeres como biológicas, no Ideológica. Entrevista com: Esther Argollo, Danitza Luna y María Galindo. Revista Arte Shock de arte contemporânea, Bolivia, 2017. [https://artishockrevista.com/2017/09/28/mujeres-c reando-entrevista/ - acesso em 10 de out 2020]

FOSTER, David William. Urban Photography in Argentina: Nine Artists of the Post-Dictatorship Era. British Library cataloguing, 2007.

FRASER, Nancy. Contra o "simbolicismo": usos e abusos do "lacanismo" para políticas feministas. Revista Lacuna. São Paulo, 20 de novembro de 2017, pp.4-9 [https://revistalacuna.com/2017/11/20/n4-09/-acesso 10 de out 2020]

GALINDO, María. No se Puede Descolonizar Sin Despatriarcalizar: teoria e propuesta de la despatriarcalización. La Paz, Ed. Mujeres Creando, 2013.

GALINDO, María. Conferência a respeito do filme "13 Horas de Rebelion". Instituto de Investigaciones Sociales - UNAM, México, 2017 [https://www.youtube.com/watch?v=ekI0n2UZ9TI - acesso em 10 de out 2020]

IRIGARAY, Luce. This sex which is not one. Ithaca e New York, Cornell University Press, 1985.

JEUDY, Henri-Pierre. O corpo Exibido. In: JEUDY, Henri-Pierre. O corpo como objeto de arte. São Paulo, Estação Liberdade, 2001, pp.109-146.

MENDONÇA, Bruna Rossetti. Agitadoras Callejeras: alianças autônomas $e$ as palavras em movimento das Mujeres Creando. Dissertação de mestrado, Antropologia - Universidade Estadual de Campinas, 2018. 
McEVILLEY, Thomas. The Triumph of Anti-Art: conceptual and performance art of pos modernism. Kingston, NY, Mcpherson\& Company, 2005.

MOURÃO, Rui. Performances artivistas: incorporação duma estética de dissensão numa ética de resistência, Dossiê Artivismo: poéticas e performances políticas na rua $e$ na rede. Cadernos de Arte $e$ Antropologia, vol. 4, n. 2, São Paulo, 2015, pp.53-69. [https://journals.openedition.org/cadernosaa/938 - acesso em 10 out 2020]

MUJERES CREANDO. Museo Nacional Centro de Arte Reina Sofía, Edificio Sabatini, Espacio Uno Ten cuidado con el presente que construyes, debe parecerse al futuro que sueñas, Puplicaciones del Museo Arte Sofia, 12 diciembre 2001 [https://www.museoreinasofia.es/exposiciones/mujeres-creando-tencuidado-presente-que-construyes-debe-parecerse-al-futuro-quesuenas - acesso em 20 de out 2020]

PAREDES, Julieta. São Paulo: Entrevista com a feminista comunitária Julieta Paredes. Justiça de Saia, São Paulo, 31 de outubro de 2017. [http://www.justicadesaia.com.br/sao-paulo-entrevista-com-afeminista-comunitaria-julieta-paredes - acesso em 10 de out, 2020]

PINHO, Armando F.; OLIVEIRA, João Manuel de. O olhar político feminista na performance artística autobiográfica. Ex Aequo, no.27, Minho, Portugal, 2012, pp.56-76 [http://www.scielo.mec.pt/pdf/aeq/n27/n27a05.pdf - acesso em 20 out 2020]

SANTOS, José Mario Peixoto. Breve histórico da "performance Art" no Brasil e no Mundo. Revista Ohun, ano 4, n. 4, Salvador, Bahia, dez 2008, pp.1-32 [http://www.revistaohun.ufba.br/pdf/ze_mario.pdf acesso em 20 de out 2020]

SOUZA, Milena da Costa. Mujeres Creando: Um espaço para abortar na $31{ }^{\text {a }}$ Bienal de São Paulo. $13^{\circ}$ Mundos de Mulheres \& Fazendo Gênero 11, Transformações, Conexões e Deslocamentos, Florianópolis, 2017 [http://www.en.wwc2017.eventos.dype.com.br/resources/anais/15242 29717 ARQUIVO ST007-MUJERESCREANDOMilenaCostadeSouza.pdf - acesso em 20 out 2020] 
SPIVAK, Gayatrí Ghakravort. Pode o subalterno falar? Belo Horizonte, Editora da UFMG, 2010.

URQUIOLA, Wara. Acepto. Latitutdes - 1 Festival Internacional de Performance Art, La Paz, Bolívia, 2018. [https://waraurquiola.wordpress.com/2018/07/04/latitudes-1er-festivalinternacional-de-performance-art/ - acesso em 10 de out 2020]

WESTCOTT, James. Quando Marina Abramovic Morrer: uma biografia. São Paulo, Edições Sesc São Paulo, 2015. 